\section{RMD Open}

Rheumatic \&

Musculoskeletal Diseases

\title{
Long-term persistence of TNF-inhibitor treatment in patients with psoriatic arthritis. Data from the British Society for Rheumatology Biologics Register
}

To cite: Fagerli KM, Kearsley-Fleet L, Watson KD, et al. Long-term persistence of TNF-inhibitor treatment in patients with psoriatic arthritis. Data from the British Society for Rheumatology Biologics Register. RMD Open 2018;4:e000596. doi:10.1136/ rmdopen-2017-000596

- Prepublication history and additional material for this paper are available online. To view these files, please visit the journal online (http://dx.doi. org/10.1136/rmdopen-2017000596).

Received 8 0ctober 2017 Revised 1 December 2017 Accepted 1 December 2017

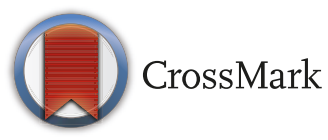

${ }^{1}$ Arthritis Research UK Centre for Epidemiology, University of Manchester, Manchester, UK ${ }^{2}$ Department of Rheumatology, Diakonhjemmet Hospital, Oslo, Norway

${ }^{3}$ Institute of Applied Clinical Sciences, Keele, UK

${ }^{4} \mathrm{NIHR}$ Manchester

Musculoskeletal Biomedical Research Unit, Manchester, UK

Correspondence to Dr Kimme L Hyrich; kimme.hyrich@manchester. ac.uk

\section{ABSTRACT}

Background Long-term effectiveness of tumour necrosis factor alpha inhibitors (TNFi) has mainly been explored in patients with rheumatoid arthritis (RA) and the data available on patients with psoriatic arthritis (PsA) includes limited follow-up.

Objective Investigate long-term effectiveness of first TNFi in a PsA population by describing treatment persistence, identify factors associated with 5-year persistence and further investigate comparative long-term effectiveness of subsequent TNFi treatments through persistence to treatment.

Methods Patients with a rheumatologist diagnosis of PsA receiving their first TNFi registered in the British Society for Rheumatology Biologics Register (BSRBR) (2002-2006) were included. Treatment at different time points was described and factors associated with 5-year treatment persistence were identified by logistic regression. KaplanMeier analysis was used to assess factors associated with persistence to first TNFi and subsequent TNFi treatments.

Results At 5 years, $46.7 \%$ of patients were still on their initial TNFi treatment. Better 5 -year persistence was associated with male gender, use of etanercept or adalimumab rather than infliximab and absence of baseline comorbidity. Five-year persistence estimates $(95 \% \mathrm{Cl})$ of first, second and third TNFi were 53\% (49\% to $57 \%$ ), $60 \%$ (43\% to $57 \%$ ) and $48 \%$ (36\% to $59 \%$ ), respectively. Conclusion We found good long-term persistence of TNFi in this PsA population both for the first and subsequent TNFi treatments. The relationship between persistence and relevant clinical factors was not strong and demonstrates the difficulties in predicting outcome of TNFi treatment in PsA.

\section{BACKGROUND}

Tumour necrosis factor alpha inhibitors (TNFi) have been shown to be efficacious in patients with psoriatic arthritis (PsA) across a number of randomised controlled trials. ${ }^{1-4}$ However, as the length of follow-up is limited, these trials provide little information on the long-term efficacy of treatments. Given the chronic nature of PsA, data on

\section{Key messages}

What is already known about this subject?

- Long-term outcomes of treatment are inadequately assessed in randomised trials, and generalisability of register data is highly influenced by the population studied.

What does this study add?

- This study provides information on long-term outcomes of tumour necrosis factor alpha inhibitors (TNFi) treatment in patients with very active polyarticular psoriatic arthritis (PsA).

- The study highlights the difficulty in identifying useful clinical predictors of successful treatment in PsA.

- Persistence of TNFi in the study population was high, particularly after switching to second and third TNFi compared with PSA populations with lower disease activity.

How might this impact on clinical practice?

- Switch to a second or third TNFi following treatment failure might still be relevant in highly active polyarticular PsA.

long-term effectiveness and tolerability are crucial. Register-based and other longitudinal observational studies have provided important insights into long-term effectiveness of treatment with TNFi in rheumatic disease, although the majority of work has been in patients with rheumatoid arthritis (RA). There are marked pathophysiological differences between PsA and RA and it cannot be assumed that RA effectiveness data can be extrapolated to PsA. Most observational studies of TNFi in PsA have focused on outcomes over a relatively short period of time and few studies have presented data on follow-up for longer than 5 years. 
Identifying factors associated with TNFi persistence in PsA has been the subject of interest in several register studies. Male gender has been identified to be associated with increased persistence to a varying degree in several studies. ${ }^{5-9}$ Treatment with concomitant methotrexate (MTX) was found to be associated with increased persistence in register data, ${ }^{81011}$ but it has been suggested that this effect may vary across different $\mathrm{TNFi}$, with most convincing increase in persistence is seen in infliximab (IFX)-treated patients on concomitant MTX. ${ }^{5}$ 12-14 Etanercept (ETN)-treated patients have been found to have increased persistence over IFX-treated patients in some studies..$^{91115}$ The association between baseline comorbidities and persistence has not been investigated by most studies, but a 2009 publication from the British Society for Rheumatology Biologics Register (BSRBR) identified absence of baseline comorbidity to be associated with increased persistence of a TNFi ${ }^{15}$ Higher baseline $\mathrm{C}$ reactive protein (CRP) has also been associated with treatment persistence. ${ }^{611}$

Persistence with a second TNFi has also been reported, but this has only included short-term follow-up. Data from the BSRBR and the Spanish Registry for Adverse Events of Biological Therapy in Rheumatic Diseases including patients from early to mid-2000s has shown similar discontinuation rates for the first and subsequent $\mathrm{TNFi}^{15}{ }^{16}$ while more recent data from the Scandinavian registers, which includes patients starting TNFi since 2010, have shown markedly lower persistence with a second and third TNFi than with the first. ${ }^{1718}$

The aim of this paper was to investigate long-term efficacy of first TNFi in a PsA population by describing treatment persistence and identify factors associated with 5 -year persistence, and further investigate comparative long-term effectiveness of subsequent TNFi treatments through persistence to treatment.

\section{METHODS}

Patients

The BSRBR was established in 2001 with the aim to monitor the long-term safety of new biologic agents in patients primarily with RA (and renamed BSRBR-RA in 2012). However, some centres also recruited patients with a rheumatologist diagnosis of PsA between March 2002 and July 2006, at which point a decision was made by the BSR to focus only on patients with RA. For this analysis, we included patients with rheumatologist-diagnosed PsA starting their first TNFi and registered within 6 months of starting this treatment. To be included, patients also had to have at least one returned clinical follow-up form in order to confirm the TNFi had been started.

\section{Baseline assessment and follow-up}

Demographics, disease characteristics, current and previous antirheumatic treatments and comorbidities were recorded at baseline (treatment start). Disease activity was assessed by the Disease Activity Score-28
(DAS28) and its components. ${ }^{19}$ Health Assessment Questionnaire (HAQ) score $^{20}$ and Medical Outcomes Study 36-item Short Form Health Survey $\left(\right.$ SF-36) ${ }^{21}$ were reported. Presence of comorbidities was extracted from the medical record and included hypertension, angina, myocardial infarction, stroke, epilepsy, asthma, chronic obstructive pulmonary disease, peptic ulcer disease, liver disease, renal disease, tuberculosis, demyelinating disease, diabetes, cancer and depression.

Patients and their rheumatologists (or rheumatology nurse specialists) were mailed follow-up questionnaires every 6 months for 3 years, and thereafter the rheumatologists/nurses were mailed follow-up questionnaires annually. Follow-up data collected included changes to treatment, adverse events and disease activity status. This analysis included data collected up until 31 January 2014.

\section{Statistical analyses}

Persistence was explored by describing treatment at 3,5 and 8 years from first TNFi start for each patient. Treatment at each point was divided into (i) continued use of first TNFi (allowing temporary pauses of up to 90 days), (ii) receiving a second/third TNFi/other treatment, (iii) no current biological treatment, (iv) lost to follow-up or (v) deceased. Lost to follow-up was defined as no returned clinical study forms for 2 years from last contact.

Five years was selected as the cut-off for long-term successful treatment with the first TNFi and univariable logistic regression was used to identify baseline factors associated with this outcome. Covariates included age, gender, disease duration, number of previously used conventional synthetic disease-modifying antirheumatic drugs (csDMARDs), TNFi type, comedication with MTX at baseline, steroid use at baseline, DAS28, erythrocyte sedimentation rate, patient global assessment (0-100), tender and swollen joints (28 joint-count), current smoking, HAQ score (0-3) and SF-36 score (mental and physical component and comorbidity (yes/no). Age, gender and variables with $P$ value $<0.25$ were included in a multivariable model and backward section was performed to fit the final model. Highly correlated measures were tested separately in the multivariable analysis.

Kaplan-Meier analysis was used additionally to explore how particular factors were associated with persistence of treatment in the different TNFi. Persistence of first TNFi by TNFi, both overall, stratified for cause of discontinuation and stratified for comedication with MTX was estimated using Kaplan-Meier analysis and compared using log-rank test. Kaplan-Meier analysis was also used to estimate persistence of a second and third course of TNFi after switching and a Cox regression was used to identify if cause of discontinuation of first TNFi was associated with persistence of a second TNFi.

\section{Results}

Of the 709 patients with PsA potentially eligible for this study, we excluded patients who had prior exposure to TNFi at point of first registration with the BSRBR $(n=84)$, 
Table 1 Baseline characteristics

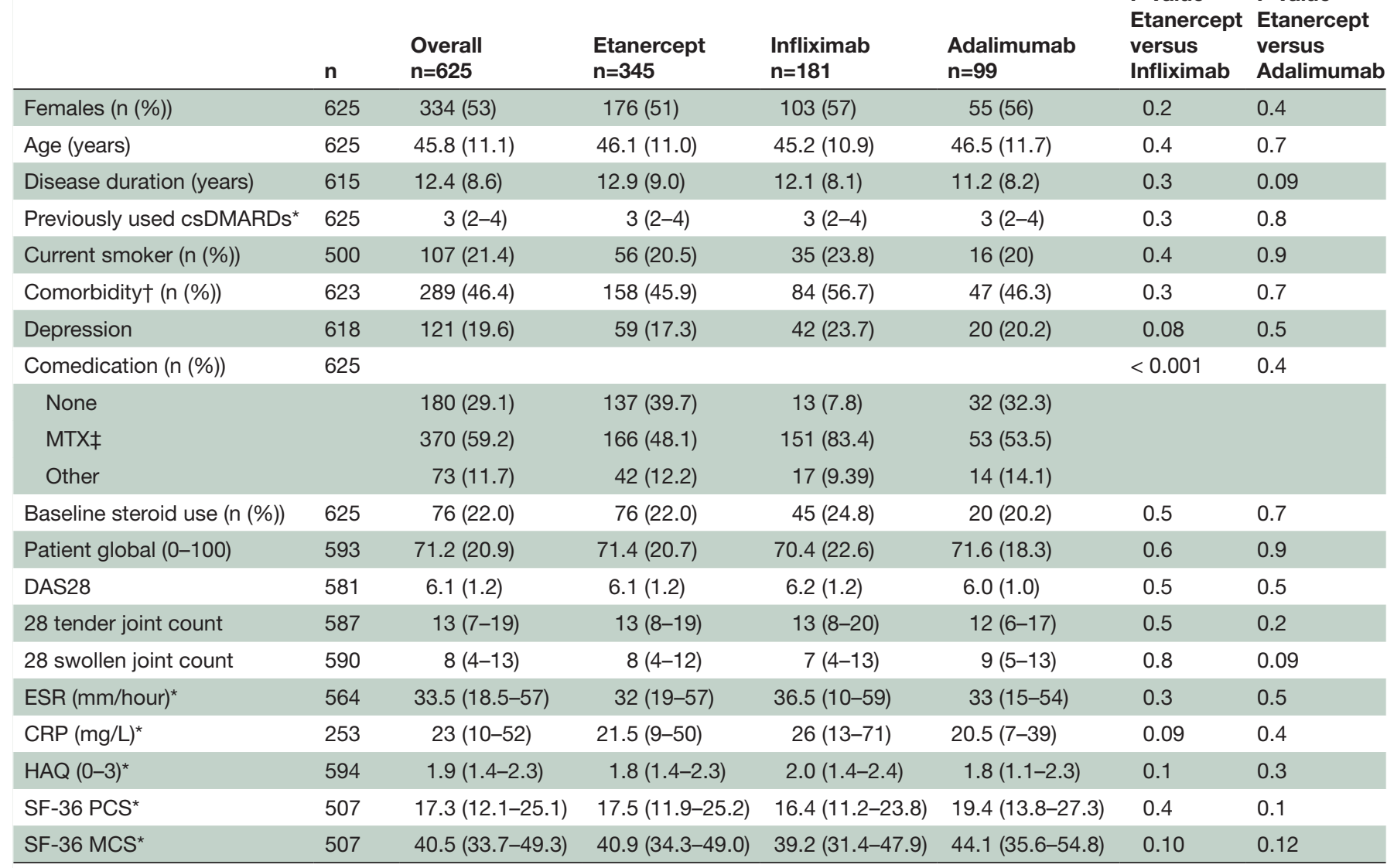

*Median (IQR).

$\dagger \geq 1$ of (previous or current) hypertension, angina, MI, stroke, epilepsy, asthma, chronic obstructive airway disease, peptic ulcer disease, liver disease, renal disease, tuberculosis, demyelinating disease, diabetes, cancer.

¥MTX only or in combination with other DMARD. Values are mean (SD) unless stated otherwise.

CRP, C reactive protein; csDMARD, conventional synthetic disease-modifying antirheumatic drug; DAS28, 28-joint Disease Activity Score;

ESR, erythrocyte sedimentation rate; HAQ, Health Assessment Questionnaire; MCS, Mental Component Score; MTX, methotrexate; n, valid observations for each variable; PCS, Physical Component Score; SF-36, medical outcomes Study 36-item Short Form Health Survey.

were registered with the BSRBR later than 6 months after initiation of their TNFi $(\mathrm{n}=41)$ and/or did not have any follow-up $(\mathrm{n}=3)$. A total of 625 patients were included and the median follow-up (IQR) was 8.0 (6.5-9.1) years. Baseline characteristics overall and for each TNFi are shown in table 1. Patients receiving different initial TNFi had similar baseline characteristics except use of MTX, which was significantly higher in the group receiving IFX.

Treatment by year after initiation is shown in table 2 . Throughout the full follow-up (until 31 January 2014), 341 patients $(54.6 \%)$ discontinued their initial treatment. Discontinuations of a first TNFi were due to inefficacy $(32.3 \%)$, adverse events $(34.9 \%)$ or other/unknown causes $(32.8 \%)$.

In univariable logistic regression several baseline variables were significantly associated with still being on the initial treatment at 5 years (table 3 ). These included male gender, using ETN or adalimumab (ADA) rather than IFX, lower HAQ and absence of comorbidity at baseline. Non-smoking, concomitant csDMARD other than MTX, no concomitant csDMARD medication and SF-36 physical component scale were borderline statistically significant in univariable analysis. Categorisation into 1 , 2 or 3 or more comorbidities at baseline yielded similar results for all categories $\geq 1$. Depression was analysed separately from the other comorbidities as we considered the effect of depression to be potentially different from other comorbidities; and the large number of patients (19.6\%) recorded to have depression allowed for this approach. However, depression showed no significant association with treatment persistence.

Age, gender, disease duration, number of previous csDMARDs used, non-infliximab TNFi versus infliximab, current smoking, HAQ, SF-36, comorbidity, depression and tender joints were included in the multivariable model. HAQ and SF-36 scores (mental and physical component scores) were entered separately, neither of them reaching statistical significance. The final model included age (included despite non-significance), gender, non-infliximab TNFi versus infliximab and comorbidity (table 3 ). 
Table 2 Treatment at 3, 5 and 8 years from baseline (n (\%))

\begin{tabular}{llll}
\hline & $\begin{array}{l}\text { 3years } \\
\mathbf{n = 6 2 5}\end{array}$ & $\begin{array}{l}\mathbf{5 y e a r s} \\
\mathbf{n = 6 2 5}\end{array}$ & $\begin{array}{l}\mathbf{8 y e a r s} \\
\mathbf{n = 4 5 4}\end{array}$ \\
\hline $\begin{array}{l}\text { Still on initial TNFi } \\
\text { Started a second TNFi }\end{array}$ & $168(27)$ & $292(47)$ & $150(33)$ \\
$\begin{array}{l}\text { within period } \\
\text { On second TNFi at time } \\
\text { point }\end{array}$ & $110(18)$ & $124(20)$ & $72(16)$ \\
$\begin{array}{l}\text { Started a third TNFi within } \\
\text { period }\end{array}$ & $39(6)$ & $62(10)$ & $96(15)$ \\
$\begin{array}{l}\text { On third or subsequent } \\
\text { TNFi at time point }\end{array}$ & $35(6)$ & $44(7)$ & $53(12)$ \\
$\begin{array}{l}\text { Started non-TNFi biologic } \\
\text { within period }\end{array}$ & $4(0.6)$ & $9(1)$ & $19(3)$ \\
$\begin{array}{l}\text { On other non-TNFi biologic } \\
\text { treatment at time point }\end{array}$ & $2(0.3)$ & $3(0.5)$ & $8(2)$ \\
$\begin{array}{l}\text { Not on biologic treatment } \\
\text { Died }\end{array}$ & $68(11)$ & $77(12)$ & $45(10)$ \\
\hline \begin{tabular}{l} 
Lost to follow-up \\
\hline
\end{tabular} & $15(2)$ & $23(4)$ & $34(8)$ \\
\hline
\end{tabular}

IFX-treated patients had a significantly higher rate of discontinuations than ETN and ADA overall (figure 1A) and due to adverse events (both $\mathrm{P}<0.001$, figure $1 \mathrm{C}$ ). Discontinuations due to inadequate response were significantly higher for IFX than ETN $(\mathrm{P}<0.001$, figure $1 \mathrm{~B})$, but not compared with ADA $(\mathrm{P}=0.14)$. Discontinuation due to adverse events was significantly higher in patients with a comorbidity than those without (HR $(95 \% \mathrm{CI}) 1.6$ (1.1 to 2.3)), while discontinuations due to inadequate response was similar (HR (95\% CI): 1.2 (0.8 to 1.7$)$ ).

Comedication with MTX was not significantly associated with 5-year persistence in the multivariable analysis. Due on findings in previous studies, we investigated this further. We found no significant differences in persistence between patients receiving MTX comedication and those who did not in a Kaplan-Meier analysis using log-rank test, either overall or separately for each TNFi (see online supplementary figure 1 ).

Throughout the observation period, 270 patients switched to a second TNFi and 111 switched to a third TNFi. Characteristics of patients who switched treatments are shown in online supplementary table 1 . Rates of discontinuation with the second and third TNFi (figure 2) were only slightly lower than the first. Five-year persistence estimates $(95 \% \mathrm{CI})$ were: 0.53 (0.49 to 0.57$)$, 0.50 (0.43 to 0.57$), 0.48$ (0.36 to 0.59$)$, respectively. Cause of discontinuation of first TNFi was not associated with persistence of second TNFi (data not shown).

\section{DISCUSSION}

This study investigated the long-term persistence with TNFi in patients with PsA. Five-year persistence with a first TNFi approached $50 \%$ and was associated with male gender, use of ETN or ADA rather than IFX, and absence of baseline comorbidity. Similar persistence estimates to the first TNFi was found following sequential initiation of second and third TNFi.

The main strength of this analysis is that we have a relatively large cohort with a long (average 8 years) follow-up time. Similar results have been presented previously from the BSRBR for the second TNFi, ${ }^{15}$ but the current results included a greater number of cases for the second TNFi (270 vs 178 ) and the follow-up time in this analysis was nearly four times longer than that previously presented. The current analysis also provides results on the use of a third TNFi.

There are a number of limitations to keep in mind when interpreting the results presented. Our analysis used treatment persistence as a surrogate of long-term effectiveness and tolerability of treatment. Our primary analysis used a logistic regression analysis and we arbitrarily defined 5 years as a cut-off for successful longterm persistence. The rationale for our approach was that assessing persistence using survival analysis would be heavily influenced by early treatment discontinuations, which were not our aim to study in this analysis. We have however included survival analysis, and both methods have limitations. The difference between the two approaches is reflected in the difference between the proportion of patients on initial treatment at 5 years shown in table 2 being under $50 \%$ and the Kaplan-Meier estimate at 5 years being 0.53 ( 0.49 to 0.57$)$. The absolute proportions presented in table 2 do not take into account the fact that patients lost to follow-up in the study may have continued treatment. Conversely, Kaplan-Maier estimations do not take into account the fact that patients who were lost to follow-up may have been more likely to have discontinued treatment than patients retained in the study. Discontinuations due to remission are another potential problem with our approach and around $10 \%$ of patients were not on any biologic treatment at 3, 5 and 8 years. However, remission was only stated as the reason for discontinuation in $0.3 \%$ of cases. In addition to this, persistence analyses are influenced by the availability of alternative treatments. In this population this has, up until recently, been limited to other TNFi, but the number of available TNFi increased over the study period. The fact that our population was recruited early in the TNFi-era with fewer TNFi available may in part explain the superior TNFi persistence observed in our cohort compared with more recent cohorts. ${ }^{17} 18$

Although the number of patients is quite large compared with previous publications, a larger sample size would have allowed us to explore results further. This is especially true for the comorbidities. We found absence of baseline comorbidity (yes/no) to be associated with 5 -year persistence, but an analysis of each of the separate comorbidities would have been a preferred approach. Better persistence in patients without baseline comorbidity is likely to be due to patients being less prone to adverse events or other medical events leading to discontinuation of their TNFi, supported by the observed higher 
Table 3 Variables associated with 5-year persistence of TNFi

\begin{tabular}{|c|c|c|c|c|}
\hline & $\begin{array}{l}\text { Univariable analysis } \\
\text { OR }(95 \% \mathrm{Cl})^{\star}\end{array}$ & $P$ value & $\begin{array}{l}\text { Multivariable analysis } \\
\text { OR }(95 \% \mathrm{Cl})^{*}\end{array}$ & $P$ value \\
\hline Females & 0.5 (0.4to 0.7$)$ & 0.0001 & $0.56(0.40$ to 0.78$)$ & $<0.001$ \\
\hline Age (years) & 1.0 (1.0 to 1.0$)$ & 0.7 & 1.01 (1.00 to 1.03$)$ & 0.08 \\
\hline Disease duration (years) & 1.0 (1.0 to 1.0$)$ & 0.2 & - & - \\
\hline Previously used csDMARDs & 0.9 (0.8 to 1.0$)$ & 0.2 & - & - \\
\hline \multicolumn{5}{|l|}{ TNFi } \\
\hline Infliximab & Ref & & Ref & \\
\hline Etanercept & 2.1 (1.5 to 3.1$)$ & 0.001 & 2.2 (1.5 to 3.2$)$ & $<0.001$ \\
\hline Adalimumab & 1.8 (1.1 to 3.0$)$ & 0.02 & $1.8(1.1$ to 3.1$)$ & 0.02 \\
\hline Current smoker & 0.7 (0.4 to 1.0$)$ & 0.05 & - & - \\
\hline Comorbidity† & 0.6 (0.4 to 0.8$)$ & 0.001 & $0.6(0.4$ to 0.8$)$ & 0.001 \\
\hline Depression & 0.8 (0.5 to 1.2$)$ & 0.2 & - & - \\
\hline \multicolumn{5}{|l|}{ Comedication } \\
\hline None & Ref & & - & - \\
\hline MTX $\ddagger$ & 0.9 (0.6 to 1.3) & 0.6 & - & - \\
\hline Other & 0.6 (0.3 to 1.0$)$ & 0.05 & - & - \\
\hline Baseline steroid use & 0.9 (0.6 to 1.4$)$ & 0.7 & - & - \\
\hline Patient global (0-100) & 1.00 (1.0 to 1.0$)$ & 0.9 & - & - \\
\hline DAS28 & 1.0 (0.9 to 1.2) & 0.9 & - & - \\
\hline 28 tender joint count & $1.0(1.0$ to 1.0$)$ & 0.1 & - & - \\
\hline 28 swollen joint count & 1.0 (1.0 to 1.0$)$ & 0.5 & - & - \\
\hline ESR (mm/hour) & $1.0(1.0$ to 1.0$)$ & 0.6 & - & - \\
\hline CRP (mg/L) & $1.0(1.0$ to 1.0$)$ & 0.4 & - & - \\
\hline HAQ (0-3) & 0.7 (0.5 to 0.9) & 0.002 & - & - \\
\hline SF-36 PCS & $1.0(1.0$ to 1.0$)$ & 0.05 & - & - \\
\hline SF-36 MCS & 1.0 (1.0 to 1.0$)$ & 0.6 & - & - \\
\hline
\end{tabular}

${ }^{*}$ Per unit increase (in continuous variables).

$\dagger \geq 1$ of (previous or current) hypertension, angina, myocardial infarction, stroke, epilepsy, asthma, chronic obstructive airway disease, peptic ulcer disease, liver disease, renal disease, tuberculosis, demyelinating disease, diabetes, cancer.

$\ddagger$ Alone or in combination with other csDMARD.

CRP, C reactive protein; csDMARD, conventional synthetic disease-modifying antirheumatic drug; DAS28, 28-joint Disease Activity Score; ESR, erythrocyte sedimentation rate; HAQ, Health Assessment Questionnaire; MCS, Mental Component Score; MTX,methotrexate; PCS, Physical Component Score; SF-36, medical outcomes Study 36-item Short Form Health Survey; TNFi, tumour necrosis factor alpha inhibitor.

rate of discontinuations due to adverse events in patients with comorbidities. However, each of the comorbidities is unlikely to carry equal weight in risk of discontinuation. Another limitation of this analysis is that comorbidities are based on clinical notes and hence likely to be heterogeneous in definition which may be particularly relevant for depression. Importantly, our results do not imply that patients who have comorbidities should have restricted access to biological treatment.

As with any observational study, bias and confounding are issues in our study. Our results show, as also shown in previous studies, that men had better treatment persistence than women. The magnitude of this difference was quite substantial in the current analyses (OR (95\% CI) for females versus males: 0.56 (0.40 to 0.78$)$ ). Potential explanations for this difference range from biological factors to differences in health seeking behaviour, most of which we have not measured and can therefore not assess further. Similarly, IFX persistence in this cohort was inferior to that of ETN and ADA and this reflects findings in other observational cohorts. ${ }^{91115}$ We cannot make any conclusions regarding the comparative effectiveness across TNFi based on our analyses as a number of factors may have contributed to the observed differences. Nearly $80 \%$ of our patients received IFX $3 \mathrm{mg} / \mathrm{kg}$ rather than the licensed $5 \mathrm{mg} / \mathrm{kg},{ }^{15}$ which may have resulted in suboptimal effectiveness. Also, patients with more serious comorbidities or issues with compliance may have been prescribed IFX to allow careful monitoring as it is administered by infusion. As subcutaneously administered TNFi became available in the study period, 

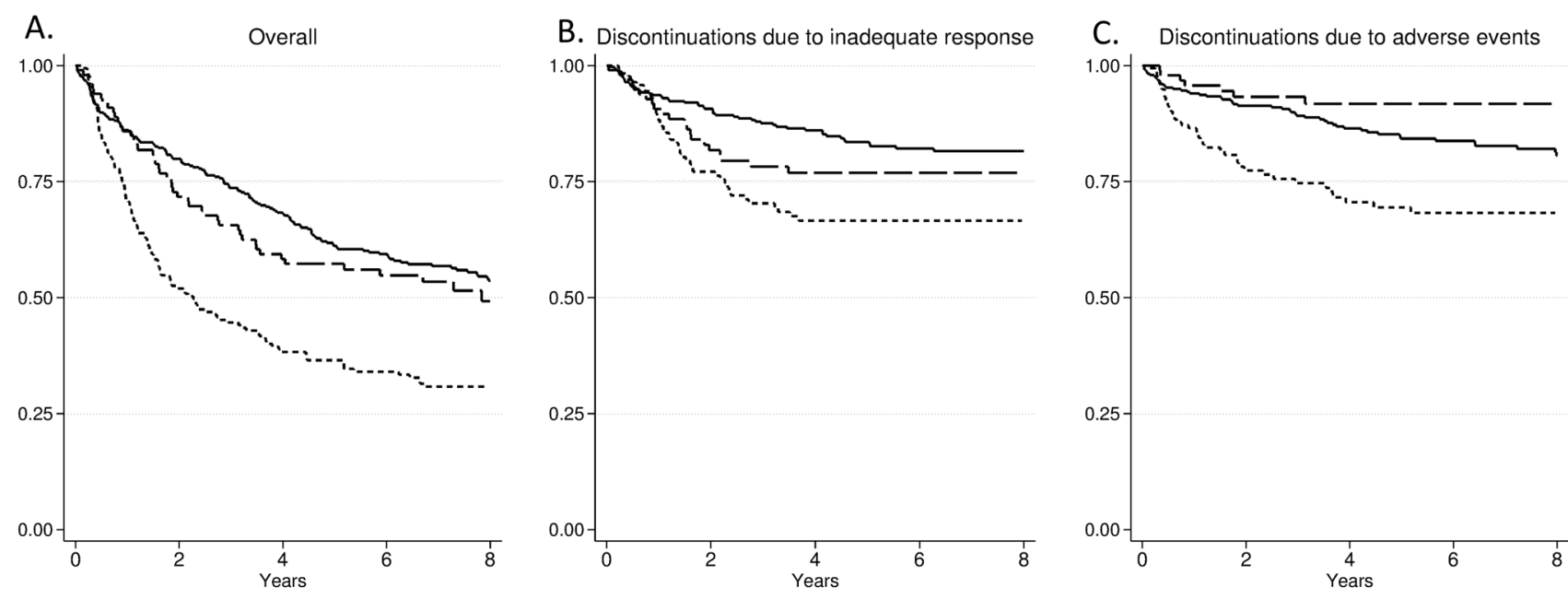

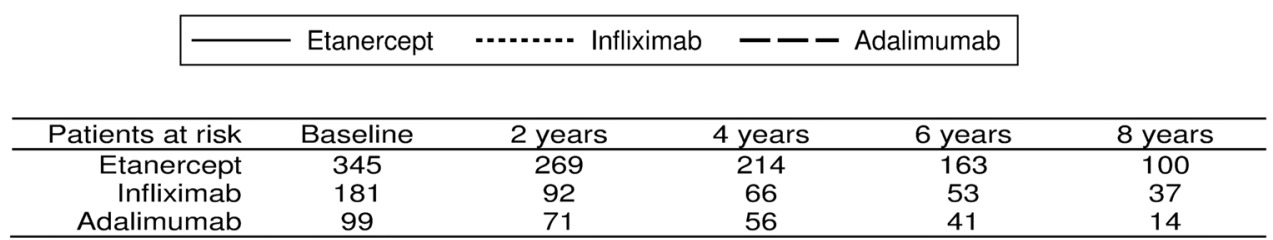

Figure 1 Persistence of first tumour necrosis factor alpha inhibitor (TNFi) by TNFi Kaplan-Meier plot of time (years) to discontinuation of treatment by TNFi. (A) All discontinuations, (B) discontinuations due to inadequate response, (C) discontinuations due to adverse events.

convenience factors may also have contributed to decisions to switch from IFX to other TNFi.

The BSRBR was largely designed to capture disease outcomes in RA and thus, the disease activity capture was limited to the DAS28 and its components. Potentially important factors such as information on joint inflammation not included in the DAS28 (importantly distal interphalangeal joints, hips and feet), as well as skin, entheseal and axial disease were not available.

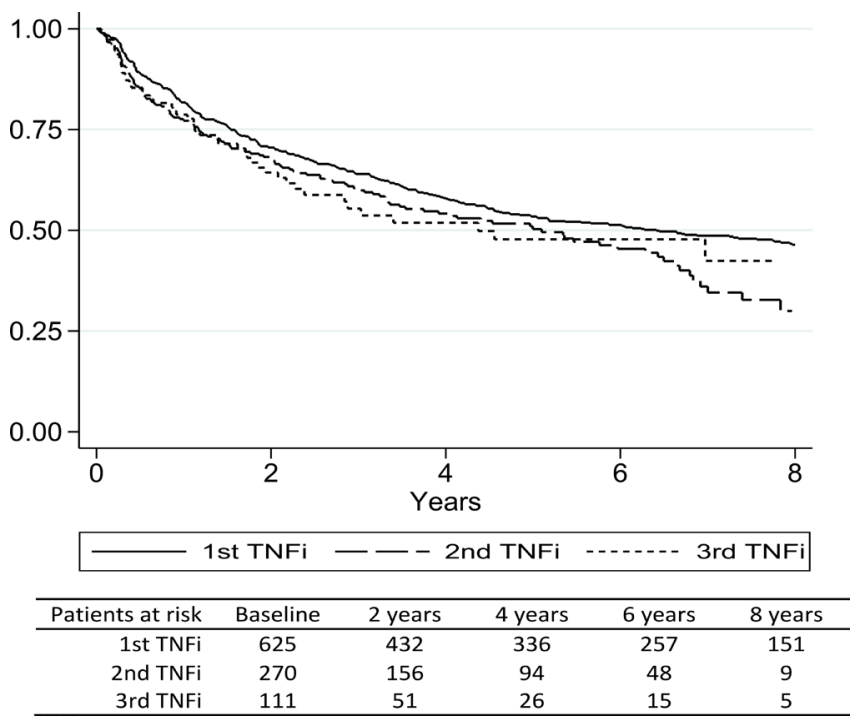

Figure 2 Persistence by course of tumour necrosis factor alpha inhibitor (TNFi) treatment Kaplan-Meier plot of time (years) to discontinuation of treatment by course of TNFi treatment.
We observed good long-term persistence for TNFi. However, both time of recruitment and local differences in prescription practices influence the generalisability of results. Most importantly, our population has a higher average disease activity than that seen in many other registries for PsA. Other registries have reported median swollen joint counts of 3 among cohorts of patients with PsA starting biologics ${ }^{56}$ while in this cohort the median swollen joint count was 8 . The patients in this cohort were also slightly older and had longer disease duration than that reported from other registries. Although licence was in place in the UK to use TNFi in patients with PsA throughout the inclusion period (2002-2006), the National Institute for Health and Care Excellence (NICE) prescribing guidelines for the use of TNFi in PsA in the UK were only published in $2006 .{ }^{22}$ The NICE criteria for RA, requiring a very high disease activity (DAS28 >5.1), may have been used instead in these patients to gain access to the treatments. This might explain part of the differences in results compared with previous studies such as the vastly superior persistence with a second and third TNFi compared with results from the Scandinavian Registers. ${ }^{17} 18$ Also, a high CRP has previously been identified to be associated with treatment persistence, ${ }^{611}$ but was not associated in our analyses which may be due to the large proportion of our patients having a high CRP. Differences in prescription practices may also influence our assessment of the importance of MTX comedication. Improved persistence when a TNFi is combined with MTX for treatment of PsA has been suggested previously, but results are most convincing for IFX ${ }^{5}{ }^{13}$ Although our 
results did not support a benefit on combining IFX with MTX, this may be explained by the fact that a majority of patients received INF with MTX $(83.4 \%)$ so any comparison is limited. For this reason, we cannot adequately assess the role of MTX comedication with IFX in this cohort. Our results however do not support an overall improved persistence on TNFi when concomitant MTX is given, and do not support such an effect in ADA.

As patients with PsA were only included in the BSRBR-RA from 2002 to 2006, the generalisability of findings in our patient cohort to that of patients currently starting a TNFi is somewhat limited as prescription practices are likely to have changed. However, the current NICE guidelines require the presence of three swollen and three tender joints to prescribe a TNFi in PsA, which is stricter than in the Scandinavian countries that have provided much of the available real-life data in PsA, and our data may therefore be of particular relevance to countries with stricter requirements to prescribe a TNFi.

In conclusion, we find that almost half of all patients with PsA starting their first TNFi during the first 5 years of TNFi availability in the UK remained on this treatment after at least 5 years. Few clinically relevant predictors of persistence to treatment could be identified despite the long follow-up time. In contrast to previous reports, comedication with MTX was not associated with increased persistence in this cohort but power to assess this in the IFX group was very limited. Persistence rate in this population with high baseline disease activity was numerically only slightly lower for a second and third TNFi, suggesting that TNFi remained a valuable treatment option for these patients over time.

Acknowledgements The authors acknowledge the enthusiastic collaboration of all consultant rheumatologists and their specialist nurses in the UK in providing the data (visit www.bsrbr.org for a full list of contributors). The authors would like to gratefully acknowledge the support of the National Institute for Health Research, through the Comprehensive Local Research Networks at participating centres. In addition, the authors acknowledge support from the BSR Executive, the members of the BSRBR Registers Committee and the BSRBR Project Team in London for their active role in enabling the register to undertake its tasks. The authors also acknowledge the seminal role of the BSR Clinical Affairs Committee for establishing national biological guidelines and recommendations for such a register. Finally, the authors would like to acknowledge the Arthritis Research UK Centre for Epidemiology, who provided the infrastructure support for the study.

Collaborators see www.bsrbr.org for full list of contributors.

Contributors KMF, JP, DPMS and KLH were responsible for the study concept and design. BSRBR Control Centre Consortium carried out acquisition of data. KMF and LK-F wrote the statistical analysis. KMF and KLH drafted the manuscript. All authors contributed to and approved the final manuscript. KMF, KDW and KLH had full access to all the data in the study and take responsibility for the integrity of the data and the accuracy of the data analysis.

Funding This work was supported by the British Society for Rheumatology (BSR). The BSR commissioned the BSR Biologics Register in rheumatoid arthritis (BSRBR-RA) as a UK-wide national project to investigate the safety of biologic agents in routine medical practice. $\mathrm{KH}$ is the principal investigator. BSR receives restricted income from the UK pharmaceutical companies, including AbbVie, Celltrion, Hospira, MSD, Pfizer, SOBI, Samsung, UCB and Roche. This income finances a wholly separate contract between the BSR and the University of Manchester. The principal investigator and the BSRBR-RA team at the University of Manchester have full academic freedom and are able to work independently of pharmaceutical industry influence. All decisions concerning analyses, interpretation and publication are made autonomously of any industrial contribution. Members of the BSRBR-RA University of Manchester team, BSR trustees, committee members and staff complete an annual declaration in relation to conflicts of interest. All relevant information regarding serious adverse events outlined in the manuscript have been reported to the appropriate pharmaceutical company as per the contractual agreements/standard operating procedures. KMF was supported through a grant from the South-Eastern Norway Regional Health Authority.

Competing interests KLH received research grants from AbbVie and Pfizer.

Ethics approval The study was approved by the North West Multicentre Research Ethics Committee (reference number MREC 00/08/053), and all subjects provided written consent

Provenance and peer review Not commissioned; externally peer reviewed. Data sharing statement No additional data are available.

Open Access This is an Open Access article distributed in accordance with the Creative Commons Attribution Non Commercial (CC BY-NC 4.0) license, which permits others to distribute, remix, adapt, build upon this work non-commercially, and license their derivative works on different terms, provided the original work is properly cited and the use is non-commercial. See: http://creativecommons.org/ licenses/by-nc/4.0/

(C) Article author(s) (or their employer(s) unless otherwise stated in the text of the article) 2018. All rights reserved. No commercial use is permitted unless otherwise expressly granted.

\section{REFERENCES}

1. Kavanaugh A, Mclnnes I, Mease P, et al. Golimumab, a new human tumor necrosis factor alpha antibody, administered every four weeks as a subcutaneous injection in psoriatic arthritis: Twenty-four-week efficacy and safety results of a randomized, placebo-controlled study. Arthritis Rheum 2009;60:976-86.

2. Mease PJ, Gladman DD, Ritchlin CT, et al. Adalimumab for the treatment of patients with moderately to severely active psoriatic arthritis: results of a double-blind, randomized, placebo-controlled trial. Arthritis Rheum 2005;52:3279-89.

3. Mease PJ, Kivitz AJ, Burch FX, et al. Etanercept treatment of psoriatic arthritis: safety, efficacy, and effect on disease progression. Arthritis Rheum 2004;50:2264-72.

4. Antoni C, Krueger GG, de Vlam K, et al. Infliximab improves signs and symptoms of psoriatic arthritis: results of the IMPACT 2 trial. Ann Rheum Dis 2005;64:1150-7.

5. Fagerli KM, Lie E, van der Heijde D, et al. The role of methotrexate co-medication in TNF-inhibitor treatment in patients with psoriatic arthritis: results from 440 patients included in the NOR-DMARD study. Ann Rheum Dis 2014;73:132-7.

6. Glintborg B, Østergaard M, Dreyer L, et al. Treatment response, drug survival, and predictors thereof in 764 patients with psoriatic arthritis treated with anti-tumor necrosis factor $\alpha$ therapy: results from the nationwide Danish DANBIO registry. Arthritis Rheum 2011;63:382-90.

7. Saad AA, Ashcroft DM, Watson KD, et al. Efficacy and safety of antiTNF therapies in psoriatic arthritis: an observational study from the British Society for Rheumatology Biologics Register. Rheumatology 2010;49:697-705.

8. Favalli EG, Selmi C, Becciolini A, et al. Eight-year retention rate of first-line tumor necrosis factor inhibitors in spondyloarthritis: A multicenter retrospective analysis. Arthritis Care Res 2016.

9. lannone F, Lopriore S, Bucci R, et al. Longterm Clinical Outcomes in 420 Patients with Psoriatic Arthritis Taking Anti-tumor Necrosis Factor Drugs in Real-world Settings. J Rheumatol 2016;43:911-7

10. Heiberg MS, Koldingsnes W, Mikkelsen $\mathrm{K}$, et al. The comparative one-year performance of anti-tumor necrosis factor alpha drugs in patients with rheumatoid arthritis, psoriatic arthritis, and ankylosing spondylitis: results from a longitudinal, observational, multicenter study. Arthritis Rheum 2008;59:234-40.

11. Kristensen LE, Gülfe A, Saxne T, et al. Efficacy and tolerability of anti-tumour necrosis factor therapy in psoriatic arthritis patients: results from the South Swedish Arthritis Treatment Group register. Ann Rheum Dis 2008;67:364-9.

12. Behrens F, Cañete JD, Olivieri I, et al. Tumour necrosis factor inhibitor monotherapy vs combination with MTX in the treatment of PsA: a systematic review of the literature. Rheumatology 2015;54:915-26.

13. Glintborg B, Gudbjornsson B, Krogh NS, et al. Impact of different infliximab dose regimens on treatment response and drug survival in 462 patients with psoriatic arthritis: results from the nationwide registries DANBIO and ICEBIO. Rheumatology 2014;53:2100-9. 
14. Mease PJ, Collier DH, Saunders KC, et al. Comparative effectiveness of biologic monotherapy versus combination therapy for patients with psoriatic arthritis: results from the Corrona registry. RMD Open 2015;1:e000181.

15. Saad AA, Ashcroft DM, Watson KD, et al. Persistence with antitumour necrosis factor therapies in patients with psoriatic arthritis: observational study from the British Society of Rheumatology Biologics Register. Arthritis Res Ther 2009;11:R52.

16. Gomez-Reino JJ, Carmona L; BIOBADASER Group. Switching TNF antagonists in patients with chronic arthritis: an observational study of 488 patients over a four-year period. Arthritis Res Ther 2006;8:R29.

17. Fagerli KM, Lie E, van der Heijde D, et al. Switching between TNF inhibitors in psoriatic arthritis: data from the NOR-DMARD study. Ann Rheum Dis 2013;72:1840-4.

18. Glintborg B, Ostergaard M, Krogh NS, et al. Clinical response, drug survival, and predictors thereof among 548 patients with psoriatic arthritis who switched tumor necrosis factor $\alpha$ inhibitor therapy: results from the Danish Nationwide DANBIO Registry. Arthritis Rheum 2013;65:1213-23.

19. Fransen J, Antoni C, Mease PJ, et al. Performance of response criteria for assessing peripheral arthritis in patients with psoriatic arthritis: analysis of data from randomised controlled trials of two tumour necrosis factor inhibitors. Ann Rheum Dis 2006;65:1373-8.

20. Pincus T, Summey JA, Soraci SA, et al. Assessment of patient satisfaction in activities of daily living using a modified Stanford Health Assessment Questionnaire. Arthritis Rheum 1983:26:1346-53.

21. Brazier J, Roberts J, Deverill M. The estimation of a preferencebased measure of health from the SF-36. $J$ Health Econ 2002;21:271-92.

22. National Institute for Health and Care Excellence. NICE technology appraisal guidance. 104, 2006. 